\title{
Challenges to Building Surveyors From The Perspectives Of Non Surveyors
}

\author{
Zarina Isnin ${ }^{1, a}$, Shamnor Syaza Dania Badrol Hisham ${ }^{1}$, Rohaslinda Ramele ${ }^{1}$, Emma Marinie Ahmad Zawawi ${ }^{1}$ \\ ${ }^{1}$ Faculty of Architecture, Planning \& Surveying, Universiti Teknologi MARA, 40450, Shah Alam, Selangor
}

\begin{abstract}
Awareness on the importance of Building Surveyors in Malaysia is still low as the role and skills of this profession are not fully understood. Although studies indicated that Building Surveyors are still in demand, even without the Building Surveyor Act, many graduates are experiencing inadequate employment opportunities in the current economic situation. Little is known on the views from other stakeholders about BS. This research aims to examine the awareness and opinions on BS in Malaysia amongst construction stakeholders. Questionnaire surveys were collected from 120 respondents from construction, maintenance and insurance companies and interviews were conducted to selected built environment respondents. It was found that awareness and knowledge on BS are still low as they lack information on the profession and professional recognitions. Some views indicated on a major identity crisis for having fragmented and disparate range of modules. The cause may have resulted in problems on public recognition, poor understanding of the surveyor's skills, and fewer job opportunities. Several suggested the profession to have a clear, coherent and relevant identity, with strong professional structures in order for the profession to survive and gain recognition from the government. Graduates are also recommended to acquire other skills and training in order for them to be significant to the construction industry.
\end{abstract}

\section{Introduction}

The construction market has been particularly hit by the downturn in the property market, and is very much exposed to macro-economic changes either in Malaysia or globally. This has affected the availability of finance for owners of property (residential, commercial and industrial) to undertake repair and refurbishment work. Fluctuations in the economy of the property and construction market affected the services and advice that clients required. There is less job opportunities for graduates. This challenging situation would instigate a need for the built environment professionals including Building Surveyors and the Building Surveying (BS) education programme to change.

Previous studies indicated that BS is a professional expertise that emerged during the 1960s and 1970s in United Kingdom (UK) because Architects were unable, or unwilling, to supervise and manage repairs and refurbishment of property. Initially, Chartered Surveyors of the Royal Institution of Chartered Surveyors (RICS) in UK with technical knowledge on maintenance and refurbishment started to take on these commissions. Degree courses on Building Surveying were then introduced to educate people wishing to enter the profession. BS is said to possess 'unique' and 'unrivalled' knowledge on legal and technical issues affecting buildings by the Association d'Experts Européens du

\footnotetext{
a Corresponding author: zarinasf@salam.uitm.edu.my
}

Bâtiments et de la Construction (AEEBC).Generally, a qualified professional Building Surveyor should be able to perform and advise upon any issues related to property and construction in respect of commercial and non domestic properties.

Although these statements indicate that the BS profession plays a very important role in construction industry, what is the current perspective in Malaysia? There are little studies carried out into exploring the views and propositions from stakeholders in construction industry about BS. Therefore, this research is an attempt to partially fill that gap in knowledge. It is hoped that the research findings from perspectives of non surveyors may act as another medium for the professional body governing building surveying in Malaysia to take a more progressive and professional approach and lead the profession into a sustainable future.

\section{Role of a Building Surveyor}

A Building Surveyor is a construction professional who provides professional advice on property and construction. The professional advice include works that involve repair, maintenance, refurbishment, alteration and extensions of all commercial, residential and industrial properties. They are also required to assess and report on defects and ways to improve a building project. They do 
not just oversee the work on building sites and measure buildings [1] but are also required to work closely with clients, construction workers and local planning bodies to ensure the building meets the required sustainability, safety and preservation standards. This is also clearly outlined in the 2016 Building Surveying Division, Royal Institution of Surveyors Malaysia (RISM) website [2].

Based on other international scope of works outlined for Building Surveyor such as RICS and Australian Institute of Building Surveyors (AIBS), building surveyors play a critical role in achieving the objects of the legislation. There is emphasise on the need for public safety and protection in relation to the design and construction of buildings. The responsibilities include drawing up detailed plans and advising on whether a grant might be available, instructing architects to prepare detailed plans and help to provide estimates for the work and dealing with planning applications, property law, building regulations and other legal matters. As there are other professionals involved in building construction project, Building Surveyor should be able to interact with other professionals.

\section{Public awareness on Building Surveying profession}

In Malaysia, studies revealed that there is still lack of public awareness on the significant establishment of BS profession [1][3][5]. The profession receives limited recognition and significance value by the Malaysian public. BS is still generally misunderstood by other professionals and the general public because there is a lack of understanding on the role of general practice surveyors profession [1][3][5]. Most of them may not realize that BS offers professional opinions on building's condition and its property value including dilapidations and condition surveys of new premises and existing buildings [5]. Furthermore, BS expertise in condition survey work is critical for the process of obtaining design information for refurbishment [4] and conservation works. The required information will actually contribute to better cost control and project management in running the refurbishment and conservation projects. However, there is less commercial publications and marketing either in articles, journals, newspapers, books or the internet about the profession [1][3].

\subsection{Professional Recognition}

BS profession has been recognised and valued in the UK, Australia, New Zealand and Hong Kong but is still hardly recognised in Europe [6]. There is evidence emerging that Building Surveyors are slowly beginning to provide professional services in the United States of America [6] although they have yet to obtain any professional recognition.

A Building Surveyor in UK was developed to be a direct response to the structure of the British Commercial property lease [7]. The profession is needed for professional advice to be provided at a level between that of the architect and the engineer [6][7]. In Australia, qualified buildings surveyors are responsible to ensure that buildings are safe, accessible and energy efficient. Their roles have an impact on the design, planning and functionality of buildings as they are able to detect and diagnose problems with design, construction techniques and materials. What about the recognition of professional Building Surveyor in Malaysia?

In Europe, the poor recognition is partly because of little awareness on the expertise, and at present there are legal constraints, and limited historic practises relating to the employment of BS professionals. Professional BS skills are deemed to be a new skill in Europe and it may encounter some difficulties because it was stated that the BS professions may lack understanding of the European regions local practices and building techniques.

A study made by Banyard, Wilkinson and Turrell [6] claimed that a principal disadvantage in the employment of Building Surveyor's from the UK is in the "limited local knowledge that they possess". The practice of Building Surveyors in certain locations could be further inhibited by difficulties to obtain building works consents and local practices. The researches further cited a study done by Linklators \& Alliance (2001), that according to French law, an Architect must be employed for building works in which planning consents are required in Europe.

In Ireland, it was acknowledged by the Society of Chartered Surveyors for Building Surveying Professional Group that there was a lack of clear professional identity of the BS profession [8]. The profession is undermined by the potential erosion of a clear professional identity by other professional groups working in the built environment such as architects and engineers. This is a weakness that makes it difficult for chartered building surveyors to fully consolidate their position in the Irish market place. The BS profession has a very narrow niche in a market which is crowded with other professional services. Furthermore, the housing market in Ireland is relatively weak which has a negative impact on the size of the market available to the profession.

\subsection{Building Surveying in Malaysia}

In Malaysia, studies stated that the most challenging task for the establishment of the BS profession is the process of gaining recognition and acceptance from other specialized professions such as architects, engineers and valuers [1]. Continuous confrontations against the establishment of the BS profession had a great impact towards the approval of the BS Act in Malaysia. Other professionals were said to be concerned about the profession and business competitions based on the BS scope of work and accountability [1][5]. These were some of the cited reasons on the constant objection towards the approval and implementation of the BS Act in Malaysia. It was further argued by the other professionals that it is not necessary to establish and endorse the BS profession because the other established professionals are competent with the knowledge, skills and ability on BS scope of works [5]. 
However, professional Building Surveyors stated that the role of BS is not to directly compete with these other professions; instead it complements and works in harmony with them [1]. As stated in other studies, it is agreed that the BS profession may benefit the construction industry because of the professional contributions on building's condition and property value. It will also create a healthy competition amongst the construction stakeholders in the building industry.

\subsection{Higher Education Programme Structure}

Previous study revealed that the syllabus offered for the BS course in higher education institutions in Malaysia varies between higher educational institutions [5]. Generally, a BS programme requires students to have a thorough understanding of construction methods and building defects. Some of the essential skills include the ability to collect data, measure accurately, take photographs, use electronic surveying devices, produce drawings, investigate thoroughly the causes of building defects, and to produce a clear written report of the findings of a survey. The survey works include building structure, electrical, plumbing and other services within the property being surveyed.

Some of the general objectives from BS programme are to ensure that students should be able to demonstrate knowledge and understanding on the role of building surveyor. The students should be able to understand the reasons for, and the processes involved, in surveying buildings. It is also vital to ensure that students be able to carry out simple building surveys, including, measured, dilapidation and condition, for domestic and commercial buildings. The students should be able to produce a survey report and schedule of maintenance and repair and distinguish between planned and unplanned maintenance. Students should be able to communicate verbally and graphically.

However, studies revealed that the previously BS syllabus offered in the public universities and private education institutions varies that created nonstandardized specific education areas [5]. Currently, the education implementation is based on the requirement set by the Malaysian Qualifications Agency (MQA) which controls and monitors quality of new programmes introduced in higher education institutions and universities. The programme structure focused on three main scope of works approved by the RISM. They are (i) Building Control; (ii) Building Maintenance and Conservation; (iii) Risk and Building Performance. The minimum credit set must be 120 . This could enhanced the quality of BS programme offered in Malaysia as the academic staff, entry requirement for the students, assessment method use and composition of subject offered can be monitored [1].

\section{Methodology}

The initial stage for this study involved literature review of primary and secondary sources to establish what had been written about BS and practice in Malaysia and the global markets. This study examine the awareness and opinions on BS in Malaysia amongst construction stakeholders. Questionnaire surveys were personally hand distributed to 300 stakeholders in construction industries such as construction, maintenance and insurance companies. 120 responses were received and analysed. Semi-structured interviews were also conducted to three professionals who are involved in construction management and one respondent is also an academician. The interviews seek to evaluate the professional views regarding BS profession in Malaysia and the barriers to practice.

The survey questionnaire was divided into four sections.

(1) Part A: The respondent's particulars using closedended questions.

They were straightforward questions to encourage respondents to participate in the survey and for easy analysis of the data.

(2) Part B: The respondent's awareness and knowledge on BS programme and recognitions using combinations of dichotomous questions for types of profession and Likert scale for their opinions on education and profession. The Likert scale required the respondent to rate their level of agreement to the statement ranging from 1 (strongly disagree) to 4 (strongly agree). The scale eliminated the mid-point ('neither... nor', uncertain etc.) category because the aim of this survey is to ascertain respondent's opinion.

(3) Part C: The respondent's opinions and perspectives on Professional Development for BS graduates using Likert scale.

(4) Part D: The respondent's recommendation to improve the BS profession using combination of Likert scale and open-ended questions. The open-ended questions were used to enable the respondents to give feedbacks with varied points of view.

Similar questions from Part C and D were also used for the semi-structured interviews to three professionals who are involved in building construction industry.

\section{Findings \& discussion}

\subsection{Demographic Profiles}

The demographic profiles demonstrated that feedbacks were received from different educational backgrounds, age, positions and years of working experience in related construction and maintenance industries. For questionnaire surveys, 120 usable responses were received during the 30 days research period. 105 respondents were from construction and maintenance companies that have experience in managing works between the range of RM3 Million to RM10 Million. Designations of respondents surveyed include project managers or building managers (6), engineers (3), quantity surveyors (4), technician or technical employee (31), administration staff (16), construction insurance specialists/employee (15) and others such as general workers and businessmen or company owner (45). 
For the interviews, three respondents agreed to be interviewed using a semi-structured questions which are similar to Part C and D in the questionnaire. They are professionals who are involved in building construction industry. Their work experience ranges from more than seven years to 25 years (R1 - Engineer; more than 7 years), R2 (Project Manager; more than 10 years) and R3 (Professional Interior Designer/ Senior Lecturer - more than 25 years). All the respondents have involved with BS graduates and professionals for their projects or work.

Table 1. Demographic finding for questionnaire survey

\begin{tabular}{|c|c|c|}
\hline Survey question & Description & $\begin{array}{c}\text { Number of } \\
\text { Respondents, } \\
\mathrm{n}\end{array}$ \\
\hline \multirow{4}{*}{$\begin{array}{l}\text { HIGHEST } \\
\text { QUALIFICATION }\end{array}$} & SPM/STPM & 49 \\
\hline & Diploma & 35 \\
\hline & Degree & 32 \\
\hline & Master & 4 \\
\hline & $20-30$ & 65 \\
\hline \multirow[t]{3}{*}{ AGE } & $31-40$ & 36 \\
\hline & $41-50$ & 17 \\
\hline & $51-60$ & 2 \\
\hline \multirow[t]{2}{*}{ GENDER } & Male & 71 \\
\hline & Female & 49 \\
\hline \multirow[t]{3}{*}{ ORGANIZATION } & Government & 7 \\
\hline & Private & 100 \\
\hline & Own Business & 13 \\
\hline \multirow[t]{7}{*}{ OCCUPATION } & Project / Building manager & 6 \\
\hline & Engineer & 3 \\
\hline & Quantity Surveyor & 4 \\
\hline & $\begin{array}{l}\text { Technician or Technical } \\
\text { employee }\end{array}$ & 31 \\
\hline & Administration staff & 16 \\
\hline & $\begin{array}{l}\text { Construction Insurance } \\
\text { Specialists/Employee }\end{array}$ & 15 \\
\hline & $\begin{array}{l}\text { Others: General worker or } \\
\text { Company owner }\end{array}$ & 45 \\
\hline
\end{tabular}

\subsection{Knowledge and Awareness on Building Surveying}

Based on the survey, $59 \%(n=71)$ do not know about the scope of works for BS. 49 respondents (40.8\%) know about professional qualifications for BS but $60 \%(n=72)$ are not familiar with the RISM.A higher percentage of respondents $(70.8 \% ; \mathrm{n}=85)$ do not know about any international recognition for BS and only $40.8 \%(n=49)$ know about RICS.57.5\% $(n=69)$ respondents were aware that there are available Diploma programmes and $75 \%$ $(n=90)$ knew about Degree programmes. 56.6\% $(n=68)$ agree and $14.2 \%(n=17)$ strongly agree that there are sufficient education opportunities for BS in Malaysia and overseas.

However, it should be noted that during the survey, majority of the respondents were actually asking for clarifications on the terms "Building Surveying" and "Building Surveyor". These findings may be related to lack of information and commercial marketing on the profession, the education programmes offered and the professional recognitions either in Malaysia or internationally. Some respondents were also asking on the similarities between quantity surveying programmes. Thus, there is a need to focus initiative about creating awareness on the work of building surveyors and the importance of building surveys.

\subsection{Potential job opportunities for BS graduates}

$61.7 \%(n=74)$ agree while $23.3 \%(n=28)$ strongly agree that the BS profession is appealing to potential entrants. Majority of the respondents $(94.2 \%)$ believed that graduates could work in BS practices such as maintenance, asset and facilities management companies, and also in heritage conservation projects. The question further asked on other career options. $69.2 \%$ have the opinions that BS graduates can work in construction companies and $67.5 \%$ selected quantity surveying companies. More than $50 \%$ of the respondents also agree that the graduates are able to work either in property development companies, town or city councils, occupational, health and safety sectors or have their own business. Majority $(78.3 \%)$ agreed that BS graduates are capable to undertake career opportunities outside Malaysia.

Based on interviews, all the three respondents believed that universities or higher education institutions especially in Malaysia should have a strategy that markets the BS diploma and degree programmes. This can be done by providing series of career talks. Two respondents (R1, R3) suggested that explanation should be given on the career options that not only focusing on Building Surveyor as the only path. In this way, it may increase the number of students significantly entering the education programme as it will ensure that all students are aware of all career paths.

\subsection{Opinions and Perspectives on Professional Development for Building Surveying Graduates}

\section{i) Professional Development}

More than $83 \%$ agree and strongly agree that there are adequate professional development for BS graduates.50.8\% $(n=61)$ agree and $37.5 \%(n=45)$ strongly agree that BS graduates should have sufficient professional expertise and skills because they are expected to provide professional advice on property and construction, which spans across residential, commercial and industrial projects.

From the interviews, all respondents (R1, R2 and R3) suggested that the current BS professionals to be more vocal and more active to support the BS profession in Malaysia. There is a need to increase the number of memberships either in RISM or RICS. R2 opined that the professional Building Surveyors are also encouraged to carry out promotion on BS throughout Malaysia. Some of the experts may establish maintenance, conservation, refurbishment or asses management guidelines and services in accordance with related Malaysian policies and standards. 
All the interviewees agreed that there should be regular professional development session to enhance their professional capabilities and opportunities in the multiprofessional construction and built environment groupings. This may lead to higher levels of professional, and public recognition.

\section{ii) Training and skill requirements}

Majority of the respondents (more than $90 \%$ from survey) and all three interviewees concurred that BS graduates would require more training before they can work as Building Surveyors or in other construction related industries. They are also encouraged to gain other skills such as on Computer Aided Design, Project Management, Facilities Management and Safety and Health trainings to prepare them for job applications. Respondents also agree that BS academic programmes require more exposures in practical trainings in order to market their potential graduates in the construction workforce.

\subsection{Recommendation to improve the BS profession - The Way Forward}

In order to survive and prosper, it is necessary for professionals to adapt to change and to maximise the opportunities that arise from change. The Building Surveyor him/herself will need to be more adaptable to construction related work practices. Building Surveyors should be able to modify their role to suite the requirements of the local professional practices as well as demands of the international markets. They will have to adjust the services that they provide depending upon the varying demands such as:

\section{i) Creating a Niche Market}

Based on interview, R2 and R3 highlighted that some of the services provided by Building Surveyor are already done by other professionals such as preparing reports on dilapidation and defects on property. International studies stated that other professionals also provide a "Building Surveying service" such as in European countries that do not have specific practising Building Surveyors. Thus, it is recommended that the Building Surveyor to identify a niche market or provide a level of service that is different from that provided by the national or international practises in the country.

For example, Building Surveyors could use their knowledge on the impact of structure, access, services, safety, health and fire protection to conservation and refurbishment projects. They should be able to comment on the effect of any proposals to the significance of the building and suggest other solutions to achieve the performance requirements that create less negative impact.

\section{ii) Upgrading the Syllabus}

R3 suggested that the scope of studies in the academic programme for $\mathrm{BS}$ is so broad. He suggested that building surveyors would then have limited depth of knowledge about too many areas. The scope of studies are only basic and may not be adequate. He further explained on the fragmentation of work that can be done by the graduates. However, R1 with more than seven years of experience positively argued that it is good for BS graduates to be equipped with broad studies related to construction, design, cost estimating, building pathology and legal requirements. She on the other hand related her experience dealing with the legal knowledge that would be beneficial especially for builders and contractors.

R2 also commented on the needs for any construction employees to have abilities for technical knowledge on construction and manual drawing skills. This is especially required to ensure the constructors understand and able to build as per specifications especially on site. However, several suggestions were made on the needs to focus the profession into specialist areas such as heritage conservation and refurbishment expert. Students are also encouraged to learn about Building Information Modelling (BIM) as this system allows for digital documentation, digital take offs and measurement linked to a pricing and costing program that will enable the construction project to be measured, priced and checked using computer technology.

Although the current education syllabus aim to provide a foundation of general building surveying and associated knowledge, it is crucial to ensure that graduates are able to read across sub-discipline areas with a reasonable measure of understanding. Specific, in-depth learning should be built upon this foundation. Students should be encouraged to possess good communication skills at all levels (written, verbal and graphic). Students and graduates should be reminded that there should be ongoing learning (both in a formal and an informal sense) for the future of their professional lives. They should also be reminded on the importance of professional structures and professional ethics.

\section{iii) Ensuring Students to Gain Hands-On Experience}

More than 30\% respondents suggested that students should be exposed to more practical training. One respondent wrote on the needs for oral, written and graphical communication skills. R3 who have experience in teaching suggested that "...it would be great to have more mature students especially those with working experience."

Students need to be trained and educated in a broad range of skills which are adaptable and flexible. This will enable them to operate in a changing and challenging market place. Providing tertiary education with a strong practical component would enable graduate to be almost immediately useful to the profession upon graduation. Graduates need to be skilled in communication and people management. 


\section{iv) Develop Better Relations with Other Professionals}

All three interviewees concurred that there is a need to better liaising with other professional bodies as this may create an opportunity to cross-sell services within the Malaysian construction and built environment industries. By selling the services through a form of "Professional Public Relation" activities and initiatives, this may educate other members and increase public information about the profession.

\section{Conclusion}

The worldwide current economic climate should instigate a need for change to $\mathrm{BS}$ to face a more challenging situations in the future. It is important to have a well defined sense of future direction and a clear plan for BS to move forward. There is a need to reflect on how to market the BS profession to recruit future generations of surveyors and how to adapt to the evolving marketplace for surveying services, before others take over those markets.

BS graduates should be able to read across subdiscipline areas with a reasonable measure of understanding. They have to acquire other skills and undergo related training in order for them to be significant in the construction industry. Although they are equipped with broad studies related to construction and maintenance, they also need to possess good communication skills at all levels. There should be lifelong learning for their professional future. There is a pressing need to create awareness on BS and the importance of professionally recognised Building Surveyors and the sustainable options it offers. This may increase student intake and awareness on career path options.

\section{References}

[1] A. S. Ali and C. J. Woon, "Training and Development of Building Surveyors in Malaysia," in RICS COBRA 2012, 2012, pp. 777-785.

[2] http://www.rism.org.my/building-surveying-divisionbs/

[3] A. S. Ali and C. J. Woon, "Issues and Challenges of Building Surveyors in Malaysia," Struct. Surv., vol. 31, no. 1, pp. 35-42, 2013.

[4] A. S. Ali, "Design information in managing refurbishment projects in Malaysia," Int. J. Phys. Sci., vol. 5, no. 6, pp. 768-773, 2010.

[5] R. A. Rashid and N. H. Ishak, "Challenges of Building Surveying Profession Establishment In Malaysia," in The Australia Institute of Building Surveyors (AIBS) 2007 International Transitions Conference, 2007, pp. 243-256.

[6] S. H. Banyard, S. J. Wilkinson, and P. Turrell, "The Impact of Globalisation on Building Surveying in Europe," Paris, France, 2003.
[7] T. Kibblewhite and S. Wilkinson, "Building Surveying: A UK Phenomenon or a Profession with Genuine Global Appeal?," Athens, Greece, 2004.

[8] Building Surveying Professional Group: Business Plan 2011 - 2014. (n.d.). Society of Chartered Surveyors Ireland. Retrieved from https://www.scsi.ie/professional groups/building su rveying/building_surveying_committee_business_pl an.final 